\title{
EDGE in Roux-en-Y gastric bypass: How does it compare to laparoscopy-assisted and balloon enteroscopy ERCP: a systematic review and meta-analysis
}

다(1)이우

\author{
Authors \\ Banreet Singh Dhindsa', Amaninder Dhaliwal², Babu P. Mohan ${ }^{3}$, Harmeet Singh Mashiana², Mohit Girotra ${ }^{4}$, \\ Shailender Singh ${ }^{2}$, Gordon Ohning ${ }^{5}$, Ishfaq Bhat ${ }^{2}$, Douglas G. Adler ${ }^{6}$
}

Institutions

1 University of Nevada Las Vegas School of Medicine, Las Vegas, Nevada, United States

2 Division of Gastroenterology and Hepatology, University of Nebraska Medical Center, Omaha, Nebraska, United States

3 Banner University Medical Center, University of Arizona, Tucson, Arizona, United States

4 Division of Gastroenterology and Hepatology, University of Miami Miller School of Medicine, Miami, Florida, United States

5 Division of Gastroenterology, University of Nevada Las Vegas School of Medicine, Las Vegas, Nevada, United States

6 Department of Gastroenterology and Hepatology, University of Utah School of Medicine, Salt Lake City, Utah

submitted 30.7 .2019

accepted after revision 15.10.2019

Bibliography

DOI https://doi.org/10.1055/a-1067-4411 |

Endoscopy International Open 2020; 08: E163-E171

(c) Georg Thieme Verlag KG Stuttgart · New York eISSN 2196-9736

Corresponding author

Douglas G. Adler, MD, FACG, AGAF, FASGE, Professor of Medicine, Director of Therapeutic endoscopy, Director, GI fellowship program, Gastroenterology and Hepatology, University of Utah School of Medicine, Huntsman Cancer Center, 30 N 1900 E, Room 4R118, Salt Lake City, Utah 84132

Fax: +1-801-581-8007

douglas.adler@hsc.utah.edu
丹 Supplementary material

Online content viewable at:

https://doi.org/10.1055/a-1067-4411

\section{ABSTRACT}

Background and study aims Endoscopic ultrasound-directed transgastric ERCP (EDGE) is a new endoscopic procedure to perform ERCP in Roux-en-y gastric bypass (RYGB) patients. The aim of this study was to conduct a systematic review and meta-analysis to evaluate technical success, clinical success and adverse effects of EDGE and compare it to laparoscopic ERCP (LA-ERCP) and balloon ERCP (BEERCP).

Patients and methods We conducted a comprehensive search of several databases and conference proceedings including PubMed, EMBASE, Google-Scholar, LILACS, SCOPUS, and Web of Science databases to identify studies reporting on EDGE, LA-ERCP, and BE-ERCP. The primary outcome was to evaluate technical and clinical success of all three procedures and the secondary analysis focused on calculating the pooled rate of all adverse events (AEs), along with the commonly reported AE subtypes.

Results Twenty-four studies on 1268 patients were included in our analysis with the majority of the population being males with mean age 53.72 years. Pooled rates of technical and clinical success with EDGE wer $95.5 \%$ and $95.9 \%$, with LA-ERCP were $95.3 \%$ and $92.9 \%$ and were BE-ERCP were $71.4 \%$ and $58.7 \%$, respectively. Pooled rates of all AEs with EDGE were $21.9 \%$, with LA-ERCP $17.4 \%$ and with BE-ERCP $8.4 \%$. Stent migration was the most common $A E$ with EDGE with $13.3 \%$ followed by bleeding with $6.6 \%$.

Conclusion Our meta-analysis demonstrated that the technical and clinical success of EDGE procedure is better than BE-ERCP and comparable to that of LA-ERCP in RYGB patients. EDGE also has a similar safety profile as compared to $L A-E R C P$ but has higher AE rate as compared to BE-ERCP. 


\section{Introduction}

Obesity is an epidemic in United States, with $35 \%$ of adults having body mass index (BMI) $>30 \mathrm{~kg} / \mathrm{m} 2$ [1]. Indications for bariatric surgery are $\mathrm{BMI}>40$ or $\mathrm{BMI}>30$ with comorbid conditions [2]. Roux-en-Y gastric bypass (RYGB) is the most commonly performed bariatric procedure in the world, consisting of $47 \%$ of the bariatric surgeries with around 200,000 surgeries performed worldwide every year [3, 4].

Rapid weight loss post-bariatric surgery is a risk factor for development of gallstones, choledocholithiasis, and pancreatitis with up to $32 \%$ to $42 \%$ of patients developing gallstones [ 5 , $6]$. Obesity can also lead to increased incidence of pancreatobiliary cancers [7]. This reflects the sheer number of patients who would potentially require biliary intervention. Endoscopic retrograde cholangiopancreatography (ERCP) in patients with RYGB is challenging for three reasons: (1) The small bowel limb to be traversed is very long and standard endoscopes and duodenoscopes are typically inadequate to reach the ampulla; (2) acute angles and stenosis at the jejunostomy site decrease the success of reaching papilla; and (3) tortuosity of the scope trajectory $[8,9]$. Various specialized procedures to perform biliary interventions in Roux-en-Y procedures include balloon enteroscopy-assisted ERCP (BE-ERCP) (single and double), spiral enteroscopy, laparoscopic-assisted ERCP (LA-ERCP) and gastrostomy tube-assisted ERCP.

BE-ERCP is commonly employed in this situation, however, due to inferior technical success it is not ideal for all patients. The reasons for the lower technical success of BE-ERCP are: (a) length of limb to be traversed; (b) absence of elevator; (c) forward viewing endoscopic view, making it difficult to cannulate; and (d) narrow diameter and long length of scopes making it hard to use the proper accessory instruments [8].

LA-ERCP has high technical success rates (papilla identification and cannulation) even though it has higher complication rates [10]. However, LA-ERCP is associated with longer hospital stays, higher hospital costs, increased complications, and requirement of multiple teams to do the procedure, all of which are disincentives to performing biliary access via this route $[11,12]$.

Endoscopic ultrasound-directed transgastric ERCP (EDGE) was first described by Kedia et al in 2014 [13]. EDGE uses a lumen-apposing metal stent (LAMS) to create a transluminal gateway from the gastric pouch or the proximal jejunal efferent limb to the remnant stomach to perform ERCP using a standard duodenoscope. In studies of EDGE, it has shown to have a high technical success rate with low risk of complications and lower hospitals costs [14-17].

The aim of this study was to evaluate technical success, clinical success, and adverse events (AEs) associated with EDGE and compare it to LA-ERCP and BE-ERCP.

\section{Patients and methods}

\section{Search strategy}

We conducted a comprehensive search of several databases and conference proceedings including PubMed, EMBASE, Google-Scholar, LILACS, SCOPUS, and Web of Science databases (earliest inception to February 2019). We followed the Preferred Reporting items for Systematic Reviews and Meta-Analyses (PRISMA) guidelines and Meta-analyses of Observational Studies in Epidemiology (MOOSE) protocol, to identify studies reporting on EDGE procedure, LA-ERCP, and BE-ERCP [18, 19]. An experienced medical librarian using inputs from the study authors helped with the literature search.

Keywords used in the literature search included a combination of 'EDGE, 'endoscopic, 'ERCP', 'GATE', 'balloon', 'enteroscopy' and 'laparoscopic'. The search was restricted to studies in human subjects and published in English language in peerreviewed journals. Two authors (BD, $A D$ ) independently reviewed the title and abstract of studies identified in primary search and excluded studies that did not address the research question, based on pre-specified exclusion and inclusion criteria. Full text of remaining articles was reviewed to determine whether it contained relevant information. Any discrepancy in article selection was resolved by consensus, and in discussion with a co-author.

Bibliographic section of the selected articles, as well as the systematic and narrative articles on the topic were manually searched for additional relevant articles.

\section{Study selection}

In this meta-analysis, we included studies that evaluated performance of EDGE, LA-ERCP, and BE-ERCP in patients with RYGB. Studies irrespective of inpatient/outpatient setting, geography, abstract/ manuscript status, were included as long as they provided data needed for the analysis.

The following were our exclusion criteria: (1) Alternative gastric bypass procedures other than RYGB; (2) studies with sample size < 10 patients; (3) studies done in pediatric population (age < 18 years); and (4) studies not published in the English language.

In cases of multiple publications from the same cohort and/ or overlapping cohorts, data from the most recent and/or most appropriate comprehensive report were included.

\section{Data abstraction and quality assessment}

Data on study-related outcomes in the individual studies were abstracted onto a standardized form by at least three authors (BD, $A D, H M)$, and two authors (BD, BPM) did the quality scoring independently.

In the situation of randomized controlled trials and casecontrol studies, data collection was done as number of reported events ( $n$ ) out of total number of patients $(N)$ from each study. The collected data were treated akin to single-group cohort studies, therefore, we used the Newcastle-Ottawa scale for cohort studies to assess the quality of studies [20]. This quality score consisted of eight questions, the details of which are provided in Supplementary Table 1. 


\section{Outcomes assessed}

Primary outcomes

1. Pooled rate of technical success: EDGE vs LA-ERCP vs BEERCP.

2. Pooled rate of clinical success: EDGE vs LA-ERCP vs BE-ERCP.

Secondary outcomes

1. Pooled rate of AEs: EDGE vs LA-ERCP vs BE-ERCP.

2. Pooled rate of AE subtypes: post-ERCP pancreatitis (PEP), bleeding, perforation, stent migration, and infection.

\section{Assessment methodology and definitions}

Collected data were matched between the groups (EDGE, LAERCP, BE-ERCP) before statistical analysis. Although, this model of comparison is indirect, and the approach is comparable to a retrospective case-control study with matched groups.

\section{Definition of outcomes}

Technical success in EDGE studies was defined as successful cannulation and deployment placement of LAMS across the fistula and successful cannulation of the desired duct in LA-ERCP and BE-ERCP studies.

Clinical success was defined as resolution of symptoms, laboratory investigations and imaging via desired therapeutic maneuvers.

AEs and their severity were reported according to the American Society of Gastrointest Endosc (ASGE) Lexicon [21].

\section{Statistical analysis}

We used meta-analysis techniques to calculate pooled estimates in each case following the methods suggested by DerSimonian and Laird using the random-effects model [22]. When incidence of an outcome was zero in a study, a continuity correction of 0.5 was added to the number of incident cases before statistical analysis [23]. We assessed heterogeneity between study-specific estimates by using Cochrane Q statistical test for heterogeneity, $95 \%$ prediction interval $(\mathrm{PI})$, which deals with the dispersion of the effects, and the 12 statistics [24, 25]. In this, values of $<30 \%, 30 \%$ to $60 \%, 61 \%$ to $75 \%$, and $>75 \%$ were suggestive of low, moderate, substantial, and considerable heterogeneity, respectively [26]. Publication bias was ascertained, qualitatively, by visual inspection of funnel plot and quantitatively, by the Egger test [27]. When publication bias was present, further statistics using the fail-Safe $\mathrm{N}$ test and Duval and Tweedie's "Trim and Fill" test was used to ascertain the impact of the bias [28]. Three levels of impact were reported based on concordance between the reported results and the actual estimate if there were no bias. The impact was reported as minimal if both versions were estimated to be same, modest if effect size changed substantially but the final finding would still remain the same, and severe if basic final conclusion of the analysis is threatened by the bias [29].

All analyses were performed using Comprehensive Meta-Analysis (CMA) software, version 3 (BioStat, Englewood, New Jersey, United States).

\section{Results}

\section{Search results and population characteristics}

From an initial 605 studies, 24 studies reported use of EDGE, BE-ERCP and LA-ERCP in RYGB patients.

In our search process, we encountered studies by Irani et al [30], Kedia 2015 et al [31], Tyberg et al [32], Kedia 2019 et al [33], and Ngamruengphong et al [34] that had overlapping cohorts. The most comprehensive studies (Chiang et al [15] and Bukhari et al [35]) were included in the final analysis.

Overall, four studies [15-17,35] provided data on EDGE, 18 studies $[11,33,36-51]$ provided data on LA-ERCP, and five studies $[35,44,49,52,53]$ provided information on BE-ERCP for our analysis.

The schematic diagram of study selection as per PRISMA guidelines and MOOSE protocol are illustrated in Supplementary Fig. 1 and Supplementary Table 1, respectively.

Baseline population characteristics were comparable between the EDGE, LA-ERCP, and BE-ERCP groups. Mean age was 53.72 years with a predominantly male population. Patient demographic characteristics are described in > Table 1 and reported AEs are summarized in $>$ Table 2 .

\section{Characteristics and quality of included studies}

Three studies were prospective, and the rest were retrospective. Seven studies were multicenter and the rest were singlecenter. None were population-based. All studies reported adequately on clinical outcomes, and assessment and factors were comparable between the study groups. Overall, 21 studies were considered of high quality, three were of medium quality. There were no low-quality studies. The detailed assessment of study quality is given in $>$ Table 3 .

\section{Meta-analysis outcomes}

A total of 1268 patients were included in the analysis. One hundred twenty-four patients from four studies underwent EDGE, 939 patients from 18 studies underwent LA-ERCP, and 205 patients from five studies underwent BE-ERCP.

\section{Primary outcomes}

1. Technical success

The calculated pooled rate of technical success ( $\nabla$ Table 4 ) with EDGE was 95.5\% (95\% Cl 84.2-98.8, 95\% PI 52 to 99.7, $12=0)$, with LA-ERCP was $95.3 \%$ (95\% Cl 91.3-97.5, $95 \% \mathrm{PI}$ 75.7 to $99,12=46.3)$, and with BE-ERCP was $71.4 \%(95 \% \mathrm{Cl}$ 51-85.7, 95\% PI 6.3 to 98.9, I2=87). Statistical p-value was significant for EDGE vs BE-ERCP, $P=0.01$ and $L A-E R C P$ vs $B E-$ ERCP, $P=0.001$ but was not significant for EDGE vs LA-ERCP, $P=0.98$.

2. Clinical success The calculated pooled rate of clinical success ( $\triangleright$ Table 4 ) with EDGE was 95.9\% (95\% Cl 81.2-99.2, $95 \%$ PI 37.5 to 99, I2 =0), with LA-ERCP was $92.9 \%(95 \% \mathrm{Cl} 83.9-97.1,95 \% \mathrm{PI}$ 14 to $99,12=84.2)$, and with BE-ERCP was $58.7 \%(95 \% \mathrm{Cl}$ 27.6-84.1, $95 \%$ PI 7.4 to $96,12=0$ ). Statistical p-value for the difference was significant for EDGE vs BE-ERCP, $P=0.001$ 
- Table 1 Description of 24 studies used in the final analysis.

\begin{tabular}{|c|c|c|c|c|c|c|c|}
\hline Author & Type of study & center & Case-control/cohort/RCT & $\begin{array}{l}\text { Mean } \\
\text { age }\end{array}$ & $\begin{array}{l}\text { Total no. } \\
\text { patients }\end{array}$ & Male & Female \\
\hline \multicolumn{8}{|l|}{ LA-ERCP } \\
\hline Abbas 2018 [11] & retrospective & multi & Cohort & 51 & 579 & 488 & 91 \\
\hline Habenicht Yancey 2018 [43] & retrospective & single & Cohort & 55.8 & 16 & $\mathrm{np}$ & $\mathrm{np}$ \\
\hline Kedia 2018 [33] & retrospective & multi & Case-control & 55 & 43 & 7 & 36 \\
\hline Frederiksen 2017 [41] & retrospective & single & Cohort & 46 & 29 & 4 & 25 \\
\hline May D 2017 [38] & retrospective & single & Cohort & np & 51 & $\mathrm{np}$ & $\mathrm{np}$ \\
\hline Bowman 2016 [37] & retrospective & multi & Cohort & 48.8 & 11 & 3 & 8 \\
\hline Farukhi 2016 [40] & retrospective & single & Cohort & np & 7 & np & $\mathrm{np}$ \\
\hline Kumar 2016 [44] & retrospective & single & Case-control & 51.5 & 19 & 2 & 17 \\
\hline Mejia 2016 [46] & retrospective & single & Cohort & 51 & 4 & 2 & 2 \\
\hline Paranandi 2016 [47] & retrospective & single & Cohort & 50.2 & 7 & 0 & 7 \\
\hline Grimes 2015 [42] & retrospective & single & Case-control & 47.8 & 38 & 2 & 36 \\
\hline Snauwaert 2015 [50] & retrospective & multi & Cohort & 54 & 21 & 5 & 18 \\
\hline Lin 2014 [45] & prospective & single & Cohort & $\mathrm{np}$ & 8 & $\mathrm{np}$ & $\mathrm{np}$ \\
\hline Sun 2014 [51] & retrospective & single & Cohort & $\mathrm{np}$ & 22 & np & $\mathrm{np}$ \\
\hline Falcão 2012 [39] & prospective & multi & Cohort & 35.3 & 23 & 4 & 19 \\
\hline Schreiner 2012 [49] & retrospective & single & Case-control & 52 & 24 & 5 & 19 \\
\hline Bertin 2011 [36] & retrospective & single & Cohort & $\mathrm{np}$ & 22 & $\mathrm{np}$ & $\mathrm{np}$ \\
\hline Saleem 2010 [48] & retrospective & single & Cohort & 50.8 & 15 & 3 & 12 \\
\hline \multicolumn{8}{|l|}{ BE-ERCP } \\
\hline Kashani 2018 [53] & retrospective & single & Cohort & 50 & 103 & 13 & 90 \\
\hline Bukhari 2018 [35] & retrospective & multi & Case-control & 61.8 & 30 & 12 & 18 \\
\hline Kumar 2016 [44] & retrospective & single & Case-control & 52.1 & 12 & 1 & 11 \\
\hline Choi 2013 [52] & retrospective & single & Case-control & 44.8 & 28 & 2 & 26 \\
\hline Schreiner 2012 [49] & retrospective & single & Case-control & 53 & 32 & 1 & 31 \\
\hline \multicolumn{8}{|l|}{ Edge } \\
\hline Wang-2019 [17] & prospective & single & Cohort & 60 & 9 & np & $\mathrm{np}$ \\
\hline Chiang 2018 [15] & retrospective & multi & Cohort & 58.3 & 66 & 20 & 46 \\
\hline James 2018 [16] & retrospective & single & Cohort & 55.5 & 19 & 4 & 15 \\
\hline Bukhari 2018 [35] & retrospective & multi & Case control & 61.8 & 30 & 12 & 18 \\
\hline
\end{tabular}

and La-ERCP vs be-ERCP, $P=0.009$. but was not significant for EDGE vs LA-ERCP, $P=0.65$.

Secondary outcomes

The pooled rates of all AEs and AE subtypes with EDGE, LAERCP, and BE-ERCP are summarized in $>$ Table 2 (Forest plots: Supplementary Fig. 2, 3, 4, 5, 6, 7, 8, 9). Pooled rates of PEP and perforation were comparable between the groups, whereas the pooled rate of bleeding with BE-ERCP was $1.5 \%$ (95\% Cl 0.4-5, 12 =0), which was significantly lower when compared to EDGE and LA-ERCP, $P=0.04$. 
- Table 2 Adverse events in all procedures

\begin{tabular}{|c|c|c|c|c|c|c|c|}
\hline Author & Total no. AE & Infection & Perforation & Bleeding & PEP & Stent dislodgement & Other \\
\hline \multicolumn{8}{|l|}{ LA-ERCP } \\
\hline Abbas 2018 [11] & 106 & 30 & 5 & 13 & 43 & 0 & 15 \\
\hline Habenicht Yancey 2018 [43] & 1 & 0 & 0 & 0 & 1 & 0 & 0 \\
\hline Kedia 2018 [33] & 8 & 3 & 2 & 1 & 0 & 0 & 2 \\
\hline Frederiksen 2017 [41] & 11 & 3 & 0 & 5 & 2 & 0 & 2 \\
\hline May D 2017 [38] & 9 & 5 & 0 & 1 & 0 & 0 & 4 \\
\hline Bowman 2016 [37] & 3 & 1 & 0 & 0 & 0 & 0 & 2 \\
\hline Farukhi 2016 [40] & 2 & 0 & 0 & 0 & 0 & 0 & 2 \\
\hline Kumar 2016 [44] & 3 & 0 & 0 & 1 & 2 & 0 & 0 \\
\hline Mejia 2016 [46] & 0 & 0 & 0 & 0 & 0 & 0 & 0 \\
\hline Paranandi 2016 [47] & 2 & 1 & 0 & 0 & 1 & 0 & 0 \\
\hline Grimes 2015 [42] & 5 & $\mathrm{np}$ & $\mathrm{np}$ & $\mathrm{np}$ & $\mathrm{np}$ & 0 & $\mathrm{np}$ \\
\hline Snauwaert 2015 [50] & 0 & 0 & 0 & 0 & 0 & 0 & 0 \\
\hline Lin 2014 [45] & 0 & 0 & 0 & 0 & 0 & 0 & 0 \\
\hline Sun 2014 [51] & 1 & 1 & 0 & 0 & 0 & 0 & 0 \\
\hline Falcão 2012 [39] & 1 & 0 & 0 & 0 & 1 & 0 & \\
\hline Schreiner 2012 [49] & 2 & 0 & 0 & 0 & 1 & 0 & 1 \\
\hline Bertin 2011 [36] & 3 & 0 & 1 & 1 & 0 & 0 & 1 \\
\hline Saleem 2010 [48] & 0 & 0 & 0 & 0 & 0 & 0 & 0 \\
\hline \multicolumn{8}{|l|}{ BE-ERCP } \\
\hline Kashani 2018 [53] & 13 & 1 & 2 & 0 & 10 & 0 & 0 \\
\hline Bukhari 2018 [35] & 3 & 1 & 1 & 0 & 1 & 0 & 0 \\
\hline Kumar 2016 [44] & 0 & 0 & 0 & 0 & 0 & 0 & 0 \\
\hline Choi 2013 [52] & 1 & 0 & 0 & 0 & 1 & 0 & 0 \\
\hline Schreiner 2012 [49] & 1 & 0 & 0 & 0 & 1 & 0 & 0 \\
\hline \multicolumn{8}{|l|}{ EDGE } \\
\hline Wang-2019 [17] & 2 & 0 & 0 & 1 & 0 & 1 & 0 \\
\hline Chiang 2018 [15] & 13 & 0 & 1 & 5 & 1 & 6 & 0 \\
\hline James 2018 [16] & 7 & 0 & 0 & 0 & 0 & 6 & 1 \\
\hline Bukhari 2018 [35] & 4 & 0 & 0 & 1 & 0 & 2 & 1 \\
\hline
\end{tabular}

\section{Validation of meta-analysis results}

Sensitivity analysis

To assess whether any one study had a dominant effect on the meta-analysis, we excluded one study at a time and analyzed its effect on the main summary estimate. On this analysis, no single study significantly affected the outcome or the heterogeneity. Therefore, including or excluding either one of the studies by Chiang et al [15] and/or Bukhari et al [35] would give us essentially the same pooled results.

\section{Heterogeneity}

We assessed dispersion of the calculated rates using the prediction interval $(\mathrm{PI})$ and $\mathrm{I} 2$ percentage values. The $\mathrm{PI}$ gives an idea of the range of the dispersion and 12 tell us what proportion of the dispersion is true vs chance [54]. The pooled rate of technical success with LA-ERCP had a narrow PI, whereas EDGE and 
- Table 3 Quality assessment of the study with Newcastle Ottawa Scale.

\begin{tabular}{|c|c|c|c|c|c|c|}
\hline \multirow[t]{2}{*}{ Author } & \multirow[t]{2}{*}{ Study type } & \multirow[t]{2}{*}{ Cohort/case-control } & \multirow[t]{2}{*}{ No.patients } & \multicolumn{3}{|c|}{ Newcastle-Ottawa Scale } \\
\hline & & & & Selection & Comparability & Outcome \\
\hline \multicolumn{7}{|l|}{ LA-ERCP } \\
\hline Abbas 2018 [11] & Retrospective & Cohort & 579 & $* * *$ & $*$ & $* * *$ \\
\hline Habenicht Yancey 2018 [41] & Retrospective & Cohort & 16 & $* * *$ & * & $* * *$ \\
\hline Kedia 2018 [31] & Retrospective & Case-control & 43 & $* * *$ & $* *$ & $* * *$ \\
\hline Frederiksen 2017 [39] & Retrospective & Cohort & 29 & $* * *$ & * & $* * *$ \\
\hline May D 2017 [36] & Retrospective & Cohort & 51 & $* * *$ & * & $* * *$ \\
\hline Bowman 2016 [35] & Retrospective & Cohort & 11 & $* * *$ & * & $* *$ \\
\hline Farukhi 2016 [38] & Retrospective & Cohort & 7 & $* *$ & * & * \\
\hline Kumar 2016 [42] & Retrospective & Case-control & 19 & $* * *$ & $* *$ & $* * *$ \\
\hline Mejia 2016 [44] & Retrospective & Cohort & 4 & $* *$ & $*$ & $* *$ \\
\hline Paranandi 2016 [45] & Retrospective & Cohort & 7 & $* * *$ & * & $* * *$ \\
\hline Grimes 2015 [40] & Retrospective & Case-control & 38 & $* * *$ & * & $* * *$ \\
\hline Snauwaert 2015 [48] & Retrospective & Cohort & 21 & $* * *$ & * & $* *$ \\
\hline Lin 2014 [43] & Prospective & Cohort & 8 & $* *$ & * & $* *$ \\
\hline Sun 2014 [49] & Retrospective & Cohort & 22 & $* *$ & * & * \\
\hline Falcão 2012 [37] & Prospective & Cohort & 23 & $* *$ & * & $* *$ \\
\hline Schreiner 2012 [47] & Retrospective & Case-control & 24 & $* * * *$ & * & $* * *$ \\
\hline Bertin 2011 [34] & Retrospective & Cohort & 22 & $* * *$ & * & $* * *$ \\
\hline Saleem 2010 [46] & Retrospective & Cohort & 15 & $* * *$ & * & $* *$ \\
\hline \multicolumn{7}{|l|}{ BE-ERCP } \\
\hline Kashani 2018 [51] & Retrospective & Cohort & 103 & $* * *$ & ${ }^{*}$ & $* * *$ \\
\hline Bukhari 2018 [33] & Retrospective & Case-control & 30 & $* * *$ & ** & $* * *$ \\
\hline Kumar 2016 [42] & Retrospective & Case-control & 12 & $* * *$ & $* *$ & $* * *$ \\
\hline Choi 2013 [50] & Retrospective & Case-control & 28 & $* * *$ & * & $* *$ \\
\hline Schreiner 2012 [47] & Retrospective & Case-control & 32 & $* * * *$ & $* *$ & $* * *$ \\
\hline \multicolumn{7}{|l|}{ EDGE } \\
\hline Wang-2019 [17] & Prospective & Cohort & 9 & $* * *$ & * & $* * *$ \\
\hline Chiang 2018 [15] & Retrospective & Cohort & 66 & $* * *$ & $*$ & * \\
\hline James 2018 [16] & Retrospective & Cohort & 19 & $* * *$ & $*$ & $* * *$ \\
\hline Bukhari 2018 [33] & Retrospective & Case control & 30 & $* * *$ & $* *$ & $* * *$ \\
\hline
\end{tabular}

be-ERCP had wide PI with heterogeneity. The PI for clinical success was wide with all the modalities, suggesting heterogeneity.

\section{Publication bias}

Based on visual inspection of the funnel plot (Supplementary Fig.10), there seemed to be possible publication bias, but quantitative measurement that used the Egger regression test, the statistical 2-tailied $P$ value was not significant for publication bias $(P=0.15)$.

\section{Discussion}

Our study demonstrated that, in patients with RYGB, EDGE procedure has comparable technical and clinical success rates to LA-ERCP and has a statistically superior technical and clinical 
Table4 Pooled rates of technical success, clinical success and adverse events of EDGE, LA-ERCP and BE-ERCP.

\begin{tabular}{|l|l|l|l|}
\hline $\begin{array}{l}\mathbf{( 9 5 \%} \mathbf{C I}, \mathbf{1 2} \%, \boldsymbol{P} \text { value in } \\
\text { comparison to EDGE) }\end{array}$ & EDGE & LA-ERCP & BE-ERCP \\
\hline Technical success & $95.5 \%(84.2-98.8,0)$ & $95.3 \%(91.3-97.5,46.3, P=0.98)$ & $71.4 \%(51-85.7,87, P=0.01)$ \\
\hline Clinical success & $95.9 \%(81.2-99.2,0)$ & $92.9 \%(83.9-97.1,84.2, P=0.65)$ & $58.7 \%(27.6-84.1,0, P=0.001)$ \\
\hline All adverse events & $21.9 \%(14.6-31.4,21.2)$ & $17.4 \%(14-21.5,18.1, P=0.32)$ & $8.4 \%(5-13.6,0, P=0.001)$ \\
\hline PEP & $2.2 \%(0.6-7.4,0)$ & $6.8 \%(5.3-8.8,0, P=0.07)$ & $6.3 \%(3.7-10.4,0, P=0.12)$ \\
\hline Bleeding & $6.6 \%(3.3-13,0)$ & $3.7 \%(2.6-5.4,5.8, P=0.15)$ & $1.5 \%(0.4-5,0, P=0.04)$ \\
\hline Perforation & $2.2 \%(0.6-7.4,0)$ & $2.2 \%(1.3-3.7,0, P=0.99)$ & $1.8 \%(0.7-4.7,0, P=0.79)$ \\
\hline Stent migration & $13.3 \%(5.7-28.1,57.6)$ & $N P$ & $N P$ \\
\hline Infection & NP & $5.8 \%(4.4-7.6,0)$ & $1.9 \%(0.7-5.2,0, P=0.04$ as compared to la-ERCP) \\
\hline
\end{tabular}

LA-ERCP, laparoscopic endoscopic retrograde cholangiopancreatography; BE-ERCP, balloon endoscopic retrograde cholangiopancreatography; EDGE, endoscopic ultrasound-directed transgastric retrograde cholangiopancreatography; PEP, post-ERCP pancreatitis; NP, not provided

success rates when compared to BE-ERCP. To our knowledge, this is the first meta-analysis comparing the outcomes of EDGE, LA-ERCP, and BE-ERCP in patients with RYGB.

Based on our analysis, the pooled rate of technical success of EDGE in RYGB patients was comparable to LA-ERCP (96.5 vs $95 \%, P=0.98$ ) but was statistically superior to BE-ERCP (96\% vs $71 \%, P=0.01)$. Similarly, the pooled clinical success rate with EDGE was comparable to LA-ERCP ( $96 \%$ vs $93 \%, P=0.65)$ and markedly superior to BE-ERCP ( $96 \%$ vs $59 \%, P=0.001$ ).

The core reason for the technical success of EDGE is the advent and commercial availability of LAMS which creates a tract for passage of the endoscope (easily bringing the papilla within reach).

Clinical success of EDGE in most the studies was also $100 \%$ $[16,17,35]$ except for one study where it was $92 \%$ [15]. The clinical success of the procedure was directly related to the technical success of the procedure, indicating the importance of a successful transluminal access procedure and operator expertise.

All AEs and subtypes of AEs (PEP, bleeding, perforation) were comparable between EDGE and LA-ERCP. However, when compared to BE-ERCP, EDGE had higher incidence of AEs. It is, however, interesting to note that rates of PEP were comparable between all the three groups. The absolute rate of PEP was the lowest with EDGE procedure and showed a trend towards statistical significance when compared to LA-ERCP.

LAMS migration was the most common AE encountered with a pooled event rate of $13.3 \%$. The main causes of stent migration are immaturity of the fistula and the manipulation of the LAMS via the duodenoscope resulting in LAMS dislodgement. This risk can potentially be reduced via performing a two-stage procedure so as to allow the fistula to mature before it is traversed. Study with a higher percentage of two-stage procedure had a lower rate of stent migration [35]. Also, lubricating the scope generously showed decreased migration in one study [33].

Weight gain is an AE that was a concern due to presence of a persistent fistula following EDGE. Only one study reported weight gain in our literature search [35]. All the other studies reported an overall average weight loss [32-35]. The reason for weight loss is unclear, but it has been hypothesized that majority of the food flows through the Roux tract and not through the fistula resulting in weight loss [33].

Failure of the fistula to close is another concerning AE for EDGE. Various techniques have been described to prevent this including exchange of LAMS with plastic stents, endoscopic suturing and OTSC (over-the scope-clips) or a combination thereof. Limited data is available on the mechanism of plastic stents and its role in closure of fistula. It works likely by irritation of mucosa resulting in granulation tissue formation resulting in closure of fistula [17]. More data are needed on this aspect to find out the best way to facilitate closure of the fistula.

The strengths of this review are as follows: systematic literature search with well-defined inclusion criteria, careful exclusion of redundant studies, inclusion of good quality studies with detailed meticulous extraction of data, rigorous evaluation of study quality, and statistics to establish and/or refute the validity of the results of our meta-analysis. Heterogeneity was minimal to zero with the pooled outcomes of EDGE. We report the prediction intervals for the primary outcomes, thereby enabling our results to be applicable to the real population. With 1268 patients and 27 studies, this is the largest, most comprehensive, and up-to-date meta-analysis evaluating and comparing EDGE, LA-ERCP, and BE-ERCP in RYGB anatomy patients.

There were limitations to this study, most of which are inherent in any meta-analysis. The included studies were not entirely representative of the general population and community practice, with most studies being performed in tertiary-care referral centers. Also, the procedure is a novel procedure and does not reflect the skill of an average endoscopist. Our analysis had studies that were retrospective in nature contributing to selection bias. Our analysis has the element of indirect comparison. Nevertheless, this study is the best available in literature thus far with respect to EDGE. More studies are warranted to better evaluate the clinical performance of EDGE procedure, especially with respect to its adverse events. 


\section{Conclusion}

In conclusion, our meta-analysis demonstrates that the technical and clinical success of EDGE procedure is better than BEERCP and comparable to that of LA-ERCP in RYGB patients. EDGE is not as expensive as LA-ERCP, minimally invasive, and can be performed by one endoscopist in one session if needed, although it is usually performed in a two-stage manner. EDGE also has a similar safety profile as compared to LA-ERCP but has higher adverse event rate as compared to BE-ERCP.

\section{Competing interests}

None

\section{References}

[1] Ogden CL, Carroll MD, Kit BK et al. Prevalence of childhood and adult obesity in the United States, 2011-2012. JAMA 2014; 311: 806-814

[2] Mechanick JI, Youdim A, Jones DB et al. Clinical practice guidelines for the perioperative nutritional, metabolic, and nonsurgical support of the bariatric surgery patient - 2013 update: cosponsored by American Association of Clinical Endocrinologists, The Obesity Society, and American Society for Metabolic \& Bariatric Surgery. Obesity 2013; 21: (Suppl. 01): S1-27

[3] Buchwald H, Oien DM. Metabolic/bariatric surgery worldwide 2011. Obes Surg 2013; 23: 427-436

[4] Angrisani L, Santonicola A, lovino P et al. IFSO Worldwide Survey 2016: Primary, Endoluminal, and Revisional Procedures. Obes Surg 2018; 28: 3783-3794

[5] Byrne TK. Complications of surgery for obesity. Surg Clin North Am 2001; 81: 1181-1193, vii-viii

[6] Villegas L, Schneider B, Provost D et al. Is routine cholecystectomy required during laparoscopic gastric bypass? Obes Surg 2004; 14 : 206-211

[7] Calle EE, Rodriguez C, Walker-Thurmond K et al. Overweight, obesity, and mortality from cancer in a prospectively studied cohort of U.S. adults. N Engl J Med 2003; 348: 1625-1638

[8] Wang TJ, Ryou M. Evolving techniques for endoscopic retrograde cholangiopancreatography in gastric bypass patients. Curr Opin Gastroenterol 2018; 34: 444-450

[9] Ross AS. Techniques for performing ERCP in Roux-en-Y gastric bypass patients. Gastroenterol Hepatol (NY) 2012; 8: 390-392

[10] da Ponte-Neto AM, Bernardo WM, de Coutinho ALM et al. Comparison between enteroscopy-based and laparoscopy-assisted ERCP for accessing the biliary tree in patients with roux-en-y gastric bypass: systematic review and meta-analysis. Obes Surg 2018; 28: 4064-4076

[11] Abbas AM, Strong AT, Diehl DL et al. Multicenter evaluation of the clinical utility of laparoscopy-assisted ERCP in patients with Roux-en-Y gastric bypass. Gastrointest Endosc 2018; 87: 1031-1039

[12] Banerjee N, Parepally M, Byrne TK et al. Systematic review of transgastric ERCP in Roux-en-Y gastric bypass patients. Surg Obes Relat Dis 2017; 13: 1236-1242

[13] Kedia P, Sharaiha RZ, Kumta NA et al. Internal EUS-directed transgastric ERCP (EDGE): game over. Gastroenterology 2014; 147: 566-568

[14] Bukhari M, Kowalski T, Nieto J et al. An international, multicenter, comparative trial of EUS-guided gastrogastrostomy-assisted ERCP versus enteroscopy-assisted ERCP in patients with Roux-en-Y gastric bypass anatomy. Gastrointest Endosc 2018; 88: 486-494
[15] Chiang AL, Gaidhane M, Loren DE et al. 338 Impact of EUS-directed transgastric ercp (edge procedure) access route on technical success and adverse events: a multi-center experience. Gastrointest Endosc 2018; 87: AB70-AB71

[16] James TW, Baron TH. Endoscopic ultrasound-directed transgastric ERCP (EDGE): a single-center us experience with follow-up data on fistula closure. Obes Surg 2019; 29: 451-456

[17] Wang T], Thompson CC, Ryou M. Gastric access temporary for endoscopy (GATE): a proposed algorithm for EUS-directed transgastric ERCP in gastric bypass patients. Surg Endosc 2019; 33: 20242033

[18] Moher D, Liberati A, Tetzlaff ] et al. Preferred reporting items for systematic reviews and meta-analyses: the PRISMA statement. Ann Intern Med 2009; 151: 264-269

[19] Stroup DF, Berlin JA, Morton SC et al. Meta-analysis of observational studies in epidemiology: a proposal for reporting. Meta-analysis Of Observational Studies in Epidemiology (MOOSE) group. JAMA 2000; 283: 2008-2012

[20] Stang A. Critical evaluation of the Newcastle-Ottawa scale for the assessment of the quality of nonrandomized studies in meta-analyses. Eur J Epidemiol 2010; 25: 603-605

[21] Cotton PB, Eisen GM, Aabakken L et al. A lexicon for endoscopic adverse events: report of an ASGE workshop. Gastrointest Endosc 2010; 71: $446-454$

[22] DerSimonian R, Laird N. Meta-analysis in clinical trials. Control Clin Trials 1986; 7: 177-188

[23] Sutton AJ, Abrams KR, Jones DR et al. Methods for meta-analysis in medical research. Wiley Chichester; 2000

[24] Higgins JPT, Thompson SG, Deeks J] et al. Measuring inconsistency in meta-analyses. BMJ 2003; 327: 557-560

[25] Kanwal F, White D. Systematic reviews and meta-analyses in clinical gastroenterology and hepatology. Clin Gastroenterol Hepat 2012; 10: 1184-1186

[26] Guyatt GH, Oxman AD, Kunz R et al. GRADE guidelines: 7. Rating the quality of evidence-inconsistency. J Clin Epidem 2011; 64: 12941302

[27] Easterbrook PJ, Gopalan R, Berlin JA et al. Publication bias in clinical research. Lancet 1991; 337: 867-872

[28] Duval S, Tweedie R. Trim and fill: a simple funnel-plot-based method of testing and adjusting for publication bias in meta-analysis. Biometrics 2000; 56: 455-463

[29] Rothstein HR, Sutton AJ, Borenstein M. Publication bias in meta-analysis: Prevention, Assessment and Adjustments. Wiley; 2005

[30] Irani S, Yang J, Khashab MA. Mitigating lumen-apposing metal stent dislodgment and allowing safe, single-stage EUS-directed transgastric ERCP. VideoGIE 2018; 3: 322-324

[31] Kedia P, Kumta NA, Sharaiha R et al. Bypassing the bypass: EUS-directed transgastric ERCP for Roux-en-Y anatomy. Gastrointest EndosC 2015; 81: 223-224

[32] Tyberg A, Nieto J, Salgado S et al. Endoscopic ultrasound (EUS)-directed transgastric endoscopic retrograde cholangiopancreatography or EUS: mid-term analysis of an emerging procedure. Clin Endosc 2017; 50: $185-190$

[33] Kedia P, Tarnasky PR, Nieto J et al. EUS-directed transgastric ERCP (EDGE) versus laparoscopy-assisted ERCP (LA-ERCP) for Roux-en-Y gastric bypass (RYGB) anatomy: a multicenter early comparative experience of clinical outcomes. J Clin Gastroenterol 2019; 53: 304-308

[34] Ngamruengphong S, Nieto J, Kunda R et al. Endoscopic ultrasoundguided creation of a transgastric fistula for the management of hepatobiliary disease in patients with Roux-en-Y gastric bypass. Endoscopy 2017; 49: 549-552

[35] Bukhari M, Kowalski T, Nieto ] et al. An international, multicenter, comparative trial of EUS-guided gastrogastrostomy-assisted ERCP 
versus enteroscopy-assisted ERCP in patients with Roux-en-Y gastric bypass anatomy. Gastrointest Endosc 2018; 88: 486-494

[36] Bertin PM, Singh K, Arregui ME. Laparoscopic transgastric endoscopic retrograde cholangiopancreatography (ERCP) after gastric bypass: case series and a description of technique. Surg Endosc 2011; 25: 2592-2596

[37] Bowman E, Greenberg J, Garren M et al. Laparoscopic-assisted ERCP and EUS in patients with prior Roux-en-Y gastric bypass surgery: a dual-center case series experience. Surg Endosc 2016; 30: 46474652

[38] May DD, Parker DM, Vogels ED et al. Outcomes of laparoscopic-assisted ERCP after Roux-En-Y gastric bypass: safe and effective for management of sphincter of Oddi dysfunction. Endosc Int Open 2019; 7: E1276-E1280

[39] Falcao M, Campos JM, Galvao Neto M et al. Transgastric endoscopic retrograde cholangiopancreatography for the management of biliary tract disease after Roux-en-Y gastric bypass treatment for obesity. Obes Surg 2012; 22: 872-876

[40] Farukhi MCB, Davis B et al. Treatment of biliary disease with transgastric ERCP after Roux-En-Y gastric bypass. Surg Endosc 2016: S325500

[41] Frederiksen NA, Tveskov L, Helgstrand F et al. Treatment of common bile duct stones in gastric bypass patients with laparoscopic transgastric endoscopic retrograde cholangiopancreatography. Obes Surg 2017; 27: 1409-1413

[42] Grimes KL, Maciel VH, Mata W et al. Complications of laparoscopic transgastric ERCP in patients with Roux-en-Y gastric bypass. Surg Endosc 2015; 29: 1753-1759

[43] Habenicht Yancey K, McCormack LK, McNatt SS et al. Laparoscopicassisted transgastric ERCP: a single-institution experience. J Obes 2018; 2018: 8275965

[44] Kumar U, Kroner PT, Jovanovic I et al. Balloon-overtube enteroscopy assisted (BAE) versus laparoscopy-assisted ERCP in Bariatric PostRoux-en-Y gastric bypass patients: a comparative study. Gastrointest Endosc 2016; 83: AB298
[45] Lin C, Aragon RJ, Carr AD et al. Direct access ERCP: a novel and reliable surgical technique for patients with Roux-en-Y anatomy. Surg Endosc 2014; 28: 311

[46] Mejia R, Achurra P, Gabrielli M et al. Laparoscopy-assisted trans-gastric rendez-vous for the treatment of common bile duct stones in patients with prior Roux-en-Y gastric bypass. Obes Surg 2016; 26: 2809 2813

[47] Paranandi B, Joshi D, Mohammadi B et al. Laparoscopy-assisted ERCP (LA-ERCP) following bariatric gastric bypass surgery: initial experience of a single UK centre. Frontline Gastroenterol 2016; 7: 54-59

[48] Saleem A, Levy MJ, Petersen BT et al. Laparoscopic assisted ERCP in Roux-en-Y gastric bypass (RYGB) surgery patients. J Gastrointest Surg 2012; 16: 203-208

[49] Schreiner MA, Chang L, Gluck M et al. Laparoscopy-assisted versus balloon enteroscopy-assisted ERCP in bariatric post-Roux-en-Y gastric bypass patients. Gastrointest Endosc 2012; 75: 748-756

[50] Snauwaert C, Laukens P, Dillemans B et al. Laparoscopy-assisted transgastric endoscopic retrograde cholangiopancreatography in bariatric Roux-en-Y gastric bypass patients. Endosc Int Open 2015; 3: E458-E463

[51] Sun Z, Rodriguez ], Albeldawi M et al. Laparoscopic transgastric endoscopic retrograde cholangiopancreatography for the treatment of biliary tract disease after Roux-en-Y gastric bypass. J Am Coll Surg 2014; 219: e60-e61

[52] Choi EK, Chiorean MV, Cote GA et al. ERCP via gastrostomy vs. double balloon enteroscopy in patients with prior bariatric Roux-en-Y gastric bypass surgery. Surg Endosc 2013; 27: 2894-2899

[53] Kashani A, Abboud G, Lo SK et al. Double balloon enteroscopy-assisted endoscopic retrograde cholangiopancreatography in RouX-en-Y gastric bypass anatomy: expert vs. novice experience. Endosc Int Open 2018; 6: E885-E891

[54] Mohan BP, Adler DG. Heterogeneity in systematic review and metaanalysis: how to read between the numbers. Gastrointest Endosc 2019; 89: 902-903 